\title{
Pulmonary function and exercise capacity in survivors of severe acute respiratory syndrome
}

\author{
K-C. Ong*, A.W-K. Ng*, L.S-U. Lee ${ }^{\#}$, G. Kaw ${ }^{\Uparrow}$, S-K. Kwek ${ }^{+}$, M.K-S. Leow ${ }^{\S}$, A. Earnest ${ }^{f}$
}

Pulmonary function and exercise capacity in survivors of severe acute respiratory syndrome. K-C. Ong, A.W-K. Ng, L.S-U. Lee, G. Kaw, S-K. Kwek, M.K-S. Leow, A. Earnest. (C) ERS Journals Ltd 2004.

ABSTRACT: The aim of this study was to investigate pulmonary function and exercise capacity in a group of survivors of the severe acute respiratory syndrome (SARS).

At 3 months after hospital discharge, 46 survivors of SARS underwent the following evaluation: spirometry, static lung volumes and carbon monoxide transfer factor $(T L, C O)$. In total, 44 of these patients underwent cardiopulmonary exercise testing.

No abnormalities were detected in the pulmonary function tests in $23(50 \%)$ of the patients. Abnormalities of forced vital capacity (FVC), forced expiratory volume in one second (FEV1), FEV1/FVC and TL,CO were detected in seven (15\%), $12(26 \%)$, one $(2 \%)$ and $18(39 \%)$ patients, respectively. All of these abnormalities were mild except in one case. In 18 patients $(41 \%)$, the maximum aerobic capacity was below the lower limit of the normal range. Breathing reserve was low in four patients and significant oxygen desaturation was detected in a further four patients. Comparison of the measured exercise capacity with resting pulmonary function tests showed many cases of discordance in impairment.

In conclusion, pulmonary function defects were detected in half of the recovered severe acute respiratory syndrome patients 3 months after hospital discharge, but the impairment was mild in almost all cases. Many patients had reduced exercise capacity that cannot be accounted for by impairment of pulmonary function.

Eur Respir J 2004; 24: 436-442.
Depts of *Respiratory Medicine, ${ }^{*}$ Infectious Diseases, ${ }^{\top}$ Diagnostic Radiology, ${ }^{+}$Psychological Medicine, ${ }^{8}$ General Medicine, and ${ }^{f}$ Clinical Epidemiology, Tan Tock Seng Hospital, Singapore.

Correspondence: K-C. Ong, Dept of Respiratory Medicine, Tan Tock Seng Hospital, 11 Jalan Tan Tock Seng, Singapore 308433. Fax: 6563577871

E-mail: kian_chung_ong@ttsh.com.sg

Keywords: Convalescence

exercise test

outcomes

pneumonia

spirometry

symptoms

Received: January 202004

Accepted after revision: April 292004

This study was supported by a grant from the A*STAR Biomedical Research Council.
Severe acute respiratory syndrome (SARS) is an acute respiratory illness caused by infection with a new coronavirus (SARS-CoV) [1]. This is a novel condition characterised by both atypical pneumonia and efficient nosocomial transmission. First recognised in mid-March 2003, SARS was successfully contained in $<4$ months. Much of what has been learned about SARS, including its causation and clinical manifestations, has been derived from studies done and observations made during the acute infection. However, knowledge about the sequelae of SARS-CoV infection remains limited.

It is well known that survivors of severe illness associated with lung injury, such as acute respiratory distress syndrome (ARDS), have persistent morbidity from lung function impairment [2]. As most patients with SARS survive the illness [3], there is a growing need to understand the long-term effects of this condition and its treatment. In Singapore, as in other countries affected by SARS, medical personnel, physicians, nurses and hospital workers are among those commonly infected. Hence, a further requirement for the identification and quantification of morbidity among survivors is for the purpose of the evaluation of impairment and disability.

The aim of this study was to investigate pulmonary function and exercise capacity in a group of SARS survivors. As all of the studied patients appear to have stabilised in their symptoms and resolution of chest radiograph (CXR) abnormalities at follow-up 3 months after hospital discharge, the current authors chose to investigate the patient population at that uniform time-point following hospital discharge.
Methods

\section{Patient selection}

There were 206 cases of SARS in Singapore that were reported to the World Health Organization (WHO) as of 26 June 2003 [4]. All of these patients were diagnosed to have "probable SARS" according to the WHO Case Definition [5] and were admitted to a single hospital (Tan Tock Seng Hospital, Singapore). Survivors at 3 months after hospital discharge were eligible for enrolment if they were $\geqslant 21$ yrs old and had duration of illness $\geqslant 12$ days from the onset of symptoms. Patients were excluded if they were immobile before being admitted to hospital for SARS, had a history of pulmonary resection or had a documented neurological or psychiatric disease. Written informed consent from patients was obtained prior to pulmonary function and exercise testing. This study was approved by the institutional ethics committee.

A total of 174 consecutive SARS survivors were evaluated for this study (fig. 1). In total, 50 patients were excluded for reasons that are outlined in figure 1 . Thirty-five patients were not included as it was already $>3$ months after their hospital discharge during the study period, which was over 10 weeks from July-September 2003. In addition, another two patients were also not included, as the time interval between hospital discharge and the study period was $<3$ months. A total of 19 patients were uncontactable and two were overseas during the study period. Of the remaining 66 patients, 20 declined to participate in this study. 


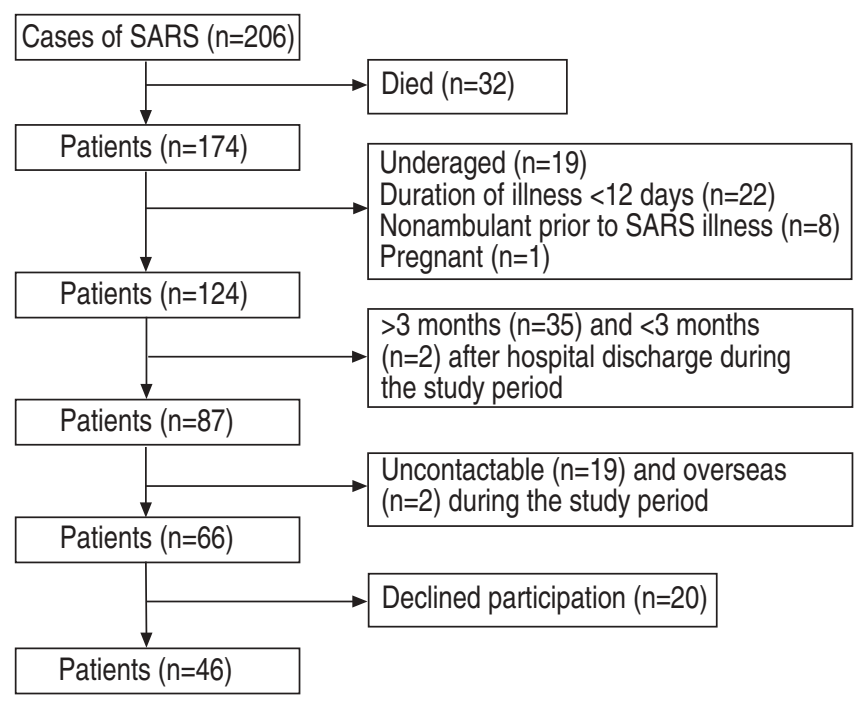

Fig. 1.-Enrolment of patients and follow-up at 3 months after hospital discharge. SARS: severe acute respiratory syndrome.

\section{Pulmonary function testing}

Pulmonary function tests performed 3 months after hospital discharge included: spirometry, measurements of total lung capacity and carbon monoxide transfer factor ( $T \mathrm{~L}, \mathrm{CO})$. Spirometry was performed in accordance with recommended standards [6]. All lung function tests were performed with the subject seated and on the same day, but before the exercise test. Forced vital capacity (FVC) and forced expiratory volume in one second (FEV1) were measured with a clinical spirometer (Vmax 229; SensorMedics, Yorba Linda, CA, USA). In accordance with the American Thoracic Society (ATS) recommendations [7], if obstruction was present, the spirometry measurements were repeated after the administration of a bronchodilator (two puffs of salbutamol) and the repeated measurements were used for analysis. Total lung capacity and its subdivisions were measured by the nitrogen washout method with the Vmax 229 (SensorMedics), adhering to standard criteria [8]. TL,CO was determined by the single-breath carbon monoxide technique [9] using an infrared analyser (Vmax 229; SensorMedics), which utilises methane as an inert tracer gas. TL,CO was adjusted for the haemoglobin concentration evaluated within 2 weeks of the pulmonary function testing, when this was available. If not, $T \mathrm{~L}, \mathrm{CO}$ was adjusted for a haemoglobin concentration of $14.6 \mathrm{~g} \cdot \mathrm{dL}^{-1}$ for males and $13.4 \mathrm{~g} \cdot \mathrm{dL}^{-1}$ for females [9]. The spirometry, lung volumes and TL,CO measurements were expressed as percentages of predicted normal values using reference values taken from the prediction equations of CHIA et al. [10] and POH and CHIA [11].

\section{Cardiopulmonary exercise testing}

The instructions given to the subjects were similar to the routine instructions sent to patients coming to the laboratory for clinical exercise testing [12]. Symptom-limited cardiopulmonary exercise testing (CPET) was performed using an electronically braked cycle ergometer (Ergometrics 800S; SensorMedics). CPET was performed under the supervision of a physician with defined criteria for stopping, such as serious cardiac arrhythmias, hypotension, electrocardiographic changes and severe oxygen desaturation. An incremental exercise protocol was used, in which the work rate was increased by $10 \mathrm{~W} \cdot \mathrm{min}^{-1}$ after an initial $3 \mathrm{~min}$ of unloaded pedalling. Standard 12-lead electrocardiograms were obtained at rest, every $3 \mathrm{~min}$ during exercise, at peak exercise and for $5 \mathrm{~min}$ into the recovery phase, whereas blood pressures were measured using a standard cuff sphygmomanometer at similar intervals. Subjects wore nose-clips and breathed through a mouthpiece connected to a pneumotachograph. Measurements of mixed expired oxygen, mixed expired carbon dioxide and expired volume were determined at rest and for each breath throughout exercise using a metabolic cart (Vmax 229; SensorMedics). The gas analyser was calibrated for accuracy and linearity prior to each test. Oxygen uptake $\left(V^{\prime} \mathrm{O}_{2}\right.$; measured in $\mathrm{mL} \cdot \mathrm{min}^{-1}$; standard temperature and pressure, dry), carbon dioxide production $\left(V^{\prime} \mathrm{CO}_{2} ;\right.$ measured in $\left.\mathrm{mL} \cdot \mathrm{min}^{-1}\right)$, gas exchange ratio, minute ventilation $\left(V^{\prime} \mathrm{E}\right.$; measured in $\mathrm{L} \cdot \mathrm{min}^{-1}$; at body temperature, ambient pressure and saturated with water vapour), respiratory rate, tidal volume $(V \mathrm{~T})$, dead space $(V \mathrm{D})$ and the ventilatory equivalent for carbon dioxide $\left(V^{\prime} \mathrm{E} / V^{\prime} \mathrm{CO}_{2}\right)$ was determined and averaged every $30 \mathrm{~s}$. The peak oxygen uptake $\left(V^{\prime} \mathrm{O}_{2}, \mathrm{max}\right), V^{\prime} \mathrm{E}$, ratio of dead space to tidal volume $(V \mathrm{D} / V \mathrm{~T})$ and heart rate $(\mathrm{HR})$ were selected as the highest values obtained from any 30-s measurement period. Maximum work rate was defined as the highest work level that was reached. The anaerobic threshold (AT) was identified for each subject using the V-slope method [13]. The $\mathrm{AT} \%$ was defined as follows:

$$
\left(V^{\prime} \mathrm{O}_{2} \text { at } \mathrm{AT} / \text { predicted } V^{\prime} \mathrm{O}_{2}, \max \right) \times 100
$$

Oxygen saturation via pulse oximetry and HR by electrocardiography were recorded continuously throughout exercise and during recovery. At the end of exercise, the reasons for termination, as well as the Borg dyspnoea score [14], were obtained from the subjects. The predicted $V^{\prime} \mathrm{O}_{2}$, max was derived from regressions based on age, sex, weight and height from published data obtained from the local population [15].

\section{Statistical analysis}

The relationship between two sets of data was analysed using the Pearson correlation test. Comparisons between groups were performed with unpaired t-tests for normally distributed continuous variables and Mann-Whitney U-tests for non-normally distributed continuous variables. Results were expressed as mean $\pm \mathrm{SD}$. The conventional level of statistical significance of 0.05 was used for all analyses.

\section{Results}

The baseline characteristics of the enrolled patients during their hospital admission for SARS are shown in table 1. A total of 23 of the 46 patients $(50 \%)$ were healthcare workers. The mean \pm SD of the percentage of lung involvement based on the worst CXR appearance during the acute illness, using a scoring system similar to that of WONG et al. [16], was $40.6 \pm 29.9 \%$. In total, 10 patients $(22 \%)$ required admission to the intensive care unit (ICU) and the mean arterial oxygen tension $\left(\mathrm{Pa}, \mathrm{O}_{2}\right)$ /inspiratory oxygen fraction $\left(\mathrm{FI}, \mathrm{O}_{2}\right)$ ratio among these patients in the ICU was 95.5 \pm 65.6 . Seven of these patients required mechanical ventilation. All seven patients had a $\mathrm{Pa}, \mathrm{O}_{2} / F \mathrm{I}, \mathrm{O}_{2}$ ratio of $\leqslant 200$ while receiving mechanical ventilation with a positive end-expiratory pressure of $\geqslant 5 \mathrm{~cm}$ of water and evidence of air-space changes in all four quadrants on CXR. Overall, three patients had a history of cigarette smoking. A total of 26 patients $(57 \%)$ had pre-existing medical conditions. The four most common preexisting illnesses were hypertension, peptic ulcer disease, diabetes mellitus and endometriosis. Eight patients (17\%) had 
Table 1.-Characteristics of patients with severe acute respiratory syndrome during hospital admission

Characteristics

Age yrs

Males \%

Pre-existing medical illnesses \%

Pre-existing pulmonary diseases $\%$

Smokers \%

Length of hospitalisation days

ICU admission \%

Highest serum LDH level $\mathrm{U} \cdot \mathrm{L}^{-1}$

Ribavarin prescription \%

Steroids prescription $\%$

Data are presented as mean \pm SD and \%. ICU: intensive care unit; LDH: lactic dehydrogenase. $n=46$.

pre-existing pulmonary disease; these were previous history of pulmonary tuberculosis $(n=3)$, pneumonia $(n=1)$, chronic bronchitis $(n=2)$ and bronchial asthma $(n=2)$.

During follow-up at 3 months after hospital discharge, 19 patients $(41 \%)$ complained of cough, $16(35 \%)$ had increased sputum production, $21(46 \%)$ had shortness of breath, and four $(9 \%)$ had occasional wheezing. All 46 patients had returned to their original work. The mean body mass index of the group at this time was $23.7 \pm 4.4$. Follow-up CXR at this time did not show any significant abnormalities except mild ground-glass opacification $(n=3)$, peripheral scarring $(n=2)$, and loculated pleural effusion in the right minor fissure $(n=1)$. The pulmonary function tests of the 46 patients are shown in table 2. The group means of FEV1, static lung volumes and diffusion capacity were all within normal limits $(>80 \%$ predicted). However, several cases of abnormalities in FVC, FEV1, FEV1/FVC ratio and TL,CO were detected. According to the ATS recommendations for evaluating respiratory impairment [7], seven patients (15\%) had mild impairment of FVC, $12(26 \%)$ had mild impairment of FEV1, one $(2 \%)$ had mild impairment of FEV1/FVC and 17 (37\%) had mild impairment of TL,CO. There was one patient $(2 \%)$ who had moderate impairment of TL,CO. As there were cases with impairment in more than one of the previous four variables,

Table 2. - Results of pulmonary function tests on follow-up

Pulmonary function tests

\section{FEV1 L}

FEV1 \% pred

FVC L

FVC \% pred

FEV $1 / \mathrm{FVC} \%$

TLC L

TLC \% pred

RV L

$\mathrm{RV} \%$ pred

FRC L

FRC $\%$ pred

VC L

$\mathrm{VC} \%$ pred

$T \mathrm{~L}, \mathrm{CO}$

$T \mathrm{~L}, \mathrm{CO} \%$ pred

$\mathrm{KCO}$

$\mathrm{KCO} \%$ pred
$2.5 \pm 0.6(1.4-4.2)$

$94.9 \pm 16.3(47.0-128.0)$ $2.9 \pm 0.8(1.8-5.5)$

$100.1 \pm 18.6(72.0-133.0)$

$86.0 \pm 6.9$ (61.0-99.0)

$4.4 \pm 1.0(2.9-8.4)$

$101.6 \pm 16.6(74.0-143.0)$ $1.4 \pm 0.4(0.7-2.7)$

$108.8 \pm 34.9$ (57.0-201.0) $2.2 \pm 0.7(1.2-4.3)$

$101.5 \pm 24.3(46.0-158.0)$ $3.0 \pm 0.8(1.9-5.7)$

$103.2 \pm 17.5$ (74.0-138.0) $6.9 \pm 1.6(4.5-11.1)$

$85.5 \pm 13.6(55.0-114.0)$ $1.7 \pm 0.2(1.2-2.4)$

$84.6 \pm 11.8(65.0-125.0)$

Data are presented as mean \pm SD (range). FEV1: forced expiratory volume in one second; FVC: forced vital capacity; TLC: total lung capacity; RV: residual volume; FRC: functional residual capacity; VC: vital capacity; $T$ L, CO: carbon monoxide transfer factor; $K C O$ : carbon monoxide transfer coefficient. $n=46$. the number of patients with mild and moderate impairment according to the above recommendations was $22(48 \%)$ and one $(2 \%)$, respectively. Table 3 shows the pulmonary function data of 23 patients who had pulmonary function abnormalities. The majority of the impairment in FEV1 and FVC suggests a restrictive abnormality, but the total lung capacity was slightly less than $80 \%$ pred in only four patients. Only one patient had obstructive abnormality with a FEV1/FVC ratio $<70 \%$ pred and this patient (patient 7 in table 3 ) had a history of poorly controlled bronchial asthma. In accordance with the ATS recommendations [7], this patient received a bronchodilator and there was improvement in FEV1 $(150 \mathrm{~mL})$ and the FEV1 \% pred $(12 \%)$ in this patient. The postbronchodilator spirometry values were used in the analysis. In 41 patients, the $T \mathrm{~L}, \mathrm{CO}$ was adjusted for a measured haemoglobin level and, in five patients, the TL,CO was adjusted with the estimated haemoglobin level.

As shown in table 3 , among patients who had pulmonary function abnormalities, eight patients had a history of medical illnesses that may affect pulmonary function. These included treated pulmonary tuberculosis, a previous episode of pneumonia, valvular heart disease, hypertension, hypothyroidism and diabetes mellitus. All of these conditions were either healed, or stable and well controlled at the time of testing during the study. The patient with valvular heart disease had mild aortic and tricuspid regurgitation with normal valve morphology, and normal left ventricular systolic and diastolic function on echocardiography.

CPET was performed in only 44 patients, as two patients refused to undergo exercise evaluation. In total, 34 patients stopped exercising due to leg fatigue, six stopped exercising due to dyspnoea and, in four patients, leg fatigue and dyspnoea were of equal intensity and limited further exercise. $V^{\prime} \mathrm{O}_{2}$, max was normal in 26 patients $(59 \%)$. Classifying impairment of measured exercise capacity [7], 10 patients $(23 \%)$ had a $V^{\prime} \mathrm{O}_{2}, \max \geqslant 25 \mathrm{~mL} \cdot \mathrm{kg}^{-1} \cdot \mathrm{min}^{-1}, 28$ patients $(64 \%)$ had a $V^{\prime} \mathrm{O}_{2}$, max $15-25 \mathrm{~mL} \cdot \mathrm{kg}^{-1} \cdot \mathrm{min}^{-1}$ and six patients $(14 \%)$ had a $V^{\prime} \mathrm{O}_{2}$, max $<15 \mathrm{~mL} \cdot \mathrm{kg}^{-1} \cdot \mathrm{min}^{-1}$. None of the patients had ventilatory limitation of exercise as defined by all three of the following criteria: 1) a ratio of the $V^{\prime} E$ at peak exercise $\left(V^{\prime} \mathrm{E}, \mathrm{max}\right)$ to the maximal voluntary ventilation (MVV; calculated as FEV1 $\times 45.12-15.85$ [16]) $>0.8$; 2) MVV$V^{\prime} \mathrm{E}, \max <12 \mathrm{~L} \cdot \mathrm{min}^{-1}$; and 3) maximum HR $<90 \%$ pred. In four patients, the breathing reserve was low and the first two of the previous criteria were achieved. Four patients had significant oxygen desaturation by pulse oximetry $>4 \%$ during incremental exercise. The peak exercise data are summarised in table 4. In 34 patients, the AT was detected during exercise testing. The mean AT $\% \pm$ SD of these patients was $69.6 \pm 12.9 \%$.

In 18 patients $(41 \%)$, the $V^{\prime} \mathrm{O}_{2}$, max was below the lower limit of the normal range, which is defined as reference value minus $1.64 \mathrm{SD}$. Among these 18 patients, the mean $V^{\prime} \mathrm{O}_{2}$, max $\%$ pred was $63 \%$, but none of the patients had a $V^{\prime} \mathrm{O}_{2}$, max $<40 \%$ pred. In total, 11 of these patients had circulatory limitation of exercise as defined by a heart rate reserve (predicted maximum heart rate (calculated as 220-age)-HR at peak exercise) $<15$ beats $\mathrm{min}^{-1}$. One of the 11 patients had combined circulatory and ventilatory limitation of exercise, as she had ventilatory limitation as defined by the following criteria: 1) a ratio of the $V^{\prime} E, \max$ to MVV [17] $>0.8$, and 2) $\mathrm{MVV}-V^{\prime} \mathrm{E}, \max <12 \mathrm{~L} \cdot \mathrm{min}^{-1}$. In the remaining seven patients, there was no evidence of circulatory or ventilatory limitation, but six of them reported leg fatigue as the predominant symptom-limiting exercise and, in one patient, the exercise limitation is likely to be due to psychogenic dyspnoea, as this patient complained of sudden onset of dyspnoea (Borg dyspnoea score 9) towards the end of unloaded cycling with refusal to continue exercise testing. Four of the 18 patients with low $V^{\prime} \mathrm{O}_{2}$, max had pre-existing medical conditions that 
Table 3. - Clinical and pulmonary function data of patients with pulmonary function impairment

\begin{tabular}{|c|c|c|c|c|c|c|c|}
\hline Patient no. & Age yrs & Pre-existing illnesses & FVC & FEV1 & FEV1/FVC & $T \mathrm{~L}, \mathrm{CO}$ & TLC \\
\hline 1 & 34 & & 91 & 90 & 90 & 73 & 99 \\
\hline 2 & 26 & & 89 & 77 & 81 & 71 & 90 \\
\hline 3 & 28 & Pneumonia & 109 & 93 & 80 & 78 & 105 \\
\hline 4 & 36 & & 90 & 78 & 79 & 95 & 103 \\
\hline 5 & 48 & VHD, hypertension, DM & 72 & 71 & 87 & 90 & 98 \\
\hline 6 & 38 & DM & 93 & 92 & 88 & 75 & 96 \\
\hline 7 & 56 & Asthma, hypertension & 90 & 64 & 61 & 108 & 110 \\
\hline 8 & 60 & & 78 & 90 & 94 & 55 & 94 \\
\hline 9 & 37 & & 89 & 91 & 92 & 77 & 97 \\
\hline 10 & 36 & & 75 & 76 & 93 & 95 & 76 \\
\hline 11 & 56 & Ankylosing spondylitis & 80 & 82 & 84 & 62 & 90 \\
\hline 12 & 45 & & 94 & 100 & 89 & 70 & 85 \\
\hline 13 & 39 & & 78 & 71 & 83 & 61 & 75 \\
\hline 14 & 22 & & 88 & 86 & 94 & 77 & 99 \\
\hline 15 & 41 & Pulmonary TB & 76 & 74 & 87 & 70 & 82 \\
\hline 16 & 37 & & 117 & 104 & 82 & 74 & 103 \\
\hline 17 & 37 & & 80 & 79 & 87 & 74 & 74 \\
\hline 18 & 41 & & 107 & 109 & 89 & 78 & 92 \\
\hline 19 & 23 & & 116 & 114 & 95 & 79 & 110 \\
\hline 20 & 21 & Pulmonary TB & 78 & 73 & 92 & 65 & 85 \\
\hline 21 & 38 & & 72 & 67 & 85 & 79 & 77 \\
\hline 22 & 34 & & 81 & 78 & 90 & 71 & 83 \\
\hline 23 & 42 & Hypothyroidism & 85 & 79 & 84 & 93 & 86 \\
\hline
\end{tabular}

Pulmonary function data are presented as percentages of predicted values except forced expiratory volume in one second (FEV1)/forced vital capacity (FVC), which is a percentage. TL,CO: carbon monoxide transfer factor; TLC: total lung capacity; VHD: valvular heart disease; DM: diabetes mellitus; TB: tuberculosis. $\mathrm{n}=23$.

may affect cardiopulmonary function. These were as follows: hypertension and ischaemic heart disease in one patient; valvular heart disease, hypertension and diabetes mellitus in one patient; diabetes mellitus in one patient; and treated pulmonary tuberculosis in another patient. None of these patients gave a history of limitation in activities of daily living, including occupational activities in patients who were working, before hospitalisation for SARS. Table 5 shows the selected parameters during exercise testing of patients with pulmonary function impairment at rest.

Comparison of the measured exercise capacity with resting pulmonary function test results showed many cases of discordance in impairment, as assessed by pulmonary function and exercise testing. In 11 of the 23 patients $(42 \%)$ with resting pulmonary function impairment, the measured exercise

Table 4.-Selected parameters at peak exercise during incremental cardiopulmonary exercise testing

\begin{tabular}{lc}
\hline $\mathrm{WR} \max \mathrm{W}$ & $95.3 \pm 30.4(0.0-164.0)^{\#}$ \\
$\mathrm{WR} \max \%$ pred & $80.0 \pm 21.2(0.0-125.3)^{\#}$ \\
$V^{\prime} \mathrm{O}_{2}, \mathrm{max} \mathrm{L} \cdot \mathrm{min}^{-1}$ & $1.2 \pm 0.4(0.6-2.2)$ \\
$V^{\prime} \mathrm{O}_{2}, \mathrm{max} / \mathrm{BW} \mathrm{mL} \cdot \mathrm{min}^{-1} \cdot \mathrm{kg}^{-1}$ & $20.3 \pm 5.1(11.2-30.6)$ \\
$V^{\prime} \mathrm{O}_{2}, \max \% \mathrm{pred}$ & $78.6 \pm 17.0(44.4-113.8)$ \\
$V^{\prime} \mathrm{E}, \max \mathrm{L} \cdot \mathrm{min}^{-1}$ & $50.2 \pm 15.7(25.3-95.4)$ \\
$\mathrm{Breathing} \mathrm{reserve} \mathrm{L} \cdot \mathrm{min}^{-1}$ & $45.7 \pm 26.4(-8.9-97.5)$ \\
$\mathrm{RER}$ & $1.1 \pm 0.1(1.0-1.3)$ \\
$\mathrm{HRmax}$ beats $\cdot \mathrm{min}^{-1}$ & $161.3 \pm 23.1(105.0-208.0)$ \\
$\mathrm{HRR}$ beats $\cdot \mathrm{min}^{-1}$ & $7 \pm 22(-37-64)$ \\
$S_{\mathrm{a}, \mathrm{O}_{2} \%} \%$ & $97.4 \pm 2.0(91.0-100.0)$ \\
$V \mathrm{D} / V \mathrm{~T}$ & $0.3 \pm 0.1(0.1-0.4)$ \\
$\mathrm{Borg}$ dyspnoea score & $3.4 \pm 2.4(0-9)$ \\
\hline
\end{tabular}

Data are presented as mean \pm SD (range). WRmax: maximum work rate; $V^{\prime} \mathrm{O}_{2}$, max: maximum oxygen uptake; $V^{\prime} \mathrm{O}_{2}, \mathrm{max} / \mathrm{BW}$ : maximum oxygen uptake per kg body weight; $V^{\prime}$ E,max: maximal minute ventilation; RER: respiratory exchange ratio; HRmax: maximum heart rate; HRR: heart rate reserve; $\mathrm{Sa}_{\mathrm{a}} \mathrm{O}_{2}$ : oxygen saturation; $V \mathrm{D} / V \mathrm{~T}$ : ratio of dead space to tidal volume. \#: one patient stopped exercise during unloaded cycling, possibly due to psychogenic dyspnoea. $n=44$. capacity was normal. In contrast, six of the 18 patients $(33 \%)$ whose measured exercise capacity was below the lower limit of the normal range did not have any resting pulmonary function impairment. Two of the four patients who had significant oxygen desaturation at peak exercise had pulmonary function impairment at rest (patient nos 8 and 23 in tables 3 and 5).

Comparing the lung function and exercise capacity of patients who required ICU care and mechanical ventilation with those who did not, there was no significant difference in FVC, FEV1, FEV1/FVC ratio, TL,CO and $V^{\prime} \mathrm{O}_{2}$, max between the two groups. There was no significant correlation between the FVC, FEV1, FEV1/FVC ratio, TL,CO and the worst CXR score [16], as well as the serum lactic dehydrogenase level, during the acute illness. Neither was there any significant correlation between these pulmonary function data and the administration of steroid or ribavarine during the acute phase of the illness.

\section{Discussion}

The main findings of this study were: 1) residual pulmonary function defects were detected in half of the recovered SARS patients 3 months after hospital discharge, but the impairment was mild in almost all cases; and 2) $41 \%$ of the patients had impairment of exercise capacity not due to ventilatory limitation.

Abnormality in TL,CO was the most common cause of impairment in pulmonary function in the patients in the current study. This finding is consistent with a follow-up study [18] of 89 patients with SARS ranging 0.5-3.4 months during the convalescent period, in which mild-to-moderate abnormalities in pulmonary function were found in 48 patients $(54 \%)$. TL,CO was impaired in 38 patients $(43 \%)$; in seven patients $(8 \%)$, lung function was restrictive defect combined with TL,CO impairment. However, direct comparison with other studies cannot be made as, unlike the present 
study, pulmonary function testing was not performed at uniform time-points in any of the previous studies on recovered SARS patients [18-20]. The findings presented here are comparable to recent studies on survivors of ARDS that have also confirmed the persistence of a low diffusion capacity as the most common abnormality in pulmonary function testing $[21,22]$.

The discordance in the results of pulmonary function and exercise testing in the present study supports the recommendation to use CPET in impairment evaluation, especially in patients with symptoms inconsistent with the degree of impairment defined by resting pulmonary function testing [23]. Recently, NEDER et al. [24] proposed expressing exercise disability using $V^{\prime} \mathrm{O}_{2}$, max $\%$ pred rather than $V^{\prime} \mathrm{O}_{2}$, max in $\mathrm{mL} \cdot \mathrm{kg}^{-1} \cdot \mathrm{min}^{-1}$, in contrast with some of the ATS recommendations [7], reasoning that the former was more useful in the evaluation of impairment. Most of the subjects (77\%) in this study had impairment defined by the ATS exercise criteria [7] $\left(V^{\prime} \mathrm{O}_{2}, \max <25 \mathrm{~mL} \cdot \mathrm{min}^{-1} \cdot \mathrm{kg}^{-1}\right)$ and $41 \%$ had impairment using $V^{\prime} \mathrm{O}_{2}$, max $\%$ pred. If impairment in exercise testing had been defined using the ATS criteria instead of comparison with predicted values, the discordance between impairment, as evaluated by exercise and resting pulmonary function tests, is likely to have been greater. Whatever the method used to define impairment in exercise capacity, the limitation in exercise of the current patients are not likely to be accounted for by pulmonary function impairment alone, as the resting pulmonary function abnormalities were generally mild. In addition, there was no evidence of exercise limitation due to ventilatory constraints solely and the number of patients with significant oxygen desaturation during exercise was very few. Nonventilatory limitation during exercise was also noted in the majority of patients in previous studies evaluating the role of exercise testing in determination of impairment in asbestos-exposed shipyard workers [25] and in patients who have recovered from severe ARDS [26].

There is an emerging body of evidence suggesting that morbidity following critical illness is multifactorial and may be viewed as a sum of physical disability and cognitive and/or psychological impairment [22]. Exercise testing, while analysing the integrated influence of multiple factors, e.g. pulmonary mechanics, pulmonary circulation, cardiac, peripheral muscle and psychosocial factors that determine an individual patient's functional level, may thus provide a more suitable assessment tool of functional outcome than resting pulmonary function tests in these patients. The present results suggest that the inability to exercise in recovered SARS patients is primarily due to extrapulmonary disease and our impression is that impaired muscle function has an important effect on the long-term outcomes of these patients. It is postulated that this may be due in part to critical-illness associated myopathy or physical deconditioning. Corticosteroid myopathy may be another contributory factor, but only a small percentage of the studied patients had received treatment with steroids during their acute illness.

The findings of this study indicate that, as with patients who have recovered from critical illness, global assessment of SARS survivors is necessary to fully comprehend the longterm physical and neuropsychological consequences of SARS. In survivors of ARDS, lung function, especially diffusion capacity, is known to improve for up to $1 \mathrm{yr}$ after discharge from the ICU $[2,22]$. Hence, further follow-up studies are imperative in determining whether the abnormalities in pulmonary function that have been identified in this study will persist and contribute to permanent impairment and disability. Future studies should also give emphasis to the evaluation of extrapulmonary causes of morbidity. The finding of reduced ability to exercise without significantly

Table 5.-Selected parameters during incremental cardiopulmonary exercise testing of patients with pulmonary function impairment

\begin{tabular}{|c|c|c|c|c|c|c|c|c|}
\hline $\begin{array}{l}\text { Patient } \\
\text { no. }\end{array}$ & $\begin{array}{l}\text { WRmax } \\
\% \text { pred }\end{array}$ & $\begin{array}{l}V^{\prime} \mathrm{O}_{2}, \max \\
\% \text { pred }\end{array}$ & $\begin{array}{c}\mathrm{BR} \\
\mathrm{L} \cdot \mathrm{min}^{-1}\end{array}$ & $\begin{array}{c}\text { HRR } \\
\text { beats } \cdot \mathrm{min}^{-1}\end{array}$ & $\begin{array}{l}V \mathrm{D} / V \mathrm{~T} \\
\text { at rest }\end{array}$ & $\begin{array}{c}V \mathrm{D} / V \mathrm{~T} \text { at } \\
\text { peak exercise }\end{array}$ & $\begin{array}{l}\text { Oxygen pulse } \\
\mathrm{mL} \cdot \text { beat }^{-1}\end{array}$ & $\mathrm{AT} \%$ \\
\hline 1 & 59.6 & 49.4 & 47.3 & 41 & 0.5 & 0.3 & 4.9 & ND \\
\hline 2 & 83.3 & 62.1 & 27.7 & 12 & 0.7 & 0.4 & 5.2 & ND \\
\hline 3 & 76.5 & 75.0 & 31.1 & -8 & 0.5 & 0.2 & 6.4 & 70.8 \\
\hline 4 & 70.6 & 68.6 & 20.2 & 11 & 0.6 & 0.3 & 5.9 & 68.6 \\
\hline 5 & 70.7 & 69.9 & 12.0 & -8 & 0.5 & 0.3 & 5.1 & 42.0 \\
\hline 6 & 62.0 & 44.4 & 69.7 & 64 & 0.6 & 0.3 & 9.6 & ND \\
\hline 7 & 98.8 & 87.2 & -8.9 & -8 & 0.5 & 0.3 & 6.4 & 75.2 \\
\hline $\begin{array}{l}8 \\
9^{\#}\end{array}$ & 79.3 & 82.0 & 28.5 & -15 & 0.4 & 0.3 & 8.2 & 68.4 \\
\hline $10^{\circ}$ & 0 & 32.3 & 50.3 & 59 & 0.4 & 0.4 & 4.8 & ND \\
\hline 11 & 76.9 & 77.3 & 22.8 & 25 & 0.6 & 0.3 & 10.3 & ND \\
\hline 12 & 63.4 & 50.9 & 93.3 & 15 & 0.4 & 0.4 & 6.4 & 51.7 \\
\hline 13 & 74.3 & 68.8 & 21.4 & 11 & 0.4 & 0.4 & 6.2 & 67.4 \\
\hline 14 & 60.0 & 66.1 & 46.4 & 29 & 0.6 & 0.3 & 6.1 & 48.2 \\
\hline 15 & 91.9 & 89.2 & 10.5 & 6 & 0.3 & 0.3 & 7.2 & 73.9 \\
\hline 16 & 85.8 & 70.6 & 59.0 & -14 & 0.3 & 0.3 & 5.3 & 61.4 \\
\hline 17 & 66.5 & 97.2 & 2.3 & -37 & 0.5 & 0.3 & 10.3 & 85.9 \\
\hline 18 & 89.2 & 100.1 & 38.1 & 6 & 0.4 & 0.2 & 12.4 & 75.7 \\
\hline 19 & 114.2 & 113.8 & 67.0 & -1 & 0.6 & 0.2 & 9.3 & 87.1 \\
\hline 20 & 67.2 & 67.7 & 32.3 & -9 & 0.5 & 0.3 & 5.4 & 57.6 \\
\hline 21 & 69.2 & 70.4 & 7.2 & 7 & 0.6 & 0.3 & 6.2 & 64.2 \\
\hline 22 & 59.7 & 53.2 & 37.8 & 15 & 0.6 & 0.4 & 5.0 & ND \\
\hline 23 & 111.8 & 99.6 & 5.1 & -22 & 0.6 & 0.3 & 7.1 & 79.8 \\
\hline
\end{tabular}

WRmax: maximum work rate; $V^{\prime} \mathrm{O}_{2}$, max: maximum oxygen uptake; $V \mathrm{D} / V \mathrm{~T}$ : ratio of dead space to tidal volume; $\mathrm{BR}$ : breathing reserve=maximal voluntary ventilation-minute ventilation at peak exercise; HRR: heart rate reserve=predicted maximum heart rate-heart rate at peak exercise; AT\%: anaerobic threshold per cent, $\mathrm{AT} \%=\left(V^{\prime} \mathrm{O}_{2}\right.$ at AT/predicted $V^{\prime} \mathrm{O}_{2}$, max $) \times 100$; ND: anaerobic threshold not detected. "\#: patient no. 9 refused to participate in exercise testing; ": patient no. 10 terminated exercise at the end of unloaded cycling. $n=23$. 
impaired lung function in most of the studied patients also suggests that emphasis on physical and psychosocial rehabilitation after their acute illness is likely to contribute to improved management of SARS patients.

There are several limitations of the current study. First, the study enrolled only a subpopulation of all the SARS cases in Singapore and, thus, the findings may not be representative of all recovered SARS cases in this or other countries. With the relatively large proportion of patients who declined evaluation 3 months after hospital discharge, there may be a bias towards selection of sicker patients with abnormal pulmonary function. This may be likely as most of these patients offered a lack of symptoms and inconvenience as the main reasons for declining participation. Secondly, 26 patients $(57 \%)$ had preexisting medical conditions, which may affect or account for the pulmonary function and exercise abnormalities that were detected. Nonetheless, we believe that the abnormalities that were detected in this study were representative of the consequences of SARS. Many of the existing medical conditions, such as peptic ulcer disease and endometriosis, were not likely to affect pulmonary function or exercise capacity. Excluding these conditions, there are only 14 patients $(30 \%)$ with medical conditions, such as hypertension, diabetes mellitus, hypothyroidism, valvular heart disease, ischaemic heart disease and all pre-existing pulmonary disease, that may possibly affect pulmonary function or exercise capacity. In addition, among the 23 patients with abnormal pulmonary function, the proportion of patients with pre-existing medical conditions that can affect pulmonary function was correspondingly small (35\%; table 3$)$. Hence, the majority of patients with impaired lung function in the current study did not have any co-existing illnesses that could have accounted for the abnormalities. Furthermore, all the pre-existing medical conditions were either healed or stable and well controlled at the time of testing during the study. With regard to pre-existing medical conditions affecting the results of cardiopulmonary exercise testing, only four of the 18 patients $(22 \%)$ with a $V^{\prime} \mathrm{O}_{2}$, max below the lower limit of the normal range had significant co-morbid conditions. Thus, the majority of these patients also did not have co-existing illnesses that could have accounted for the impaired exercise capacity. Thirdly, the heterogeneity of acute lung disease, encompassed by the case definition of SARS, may account for the observed variation in pulmonary and extrapulmonary sequelae among the studied patients. Fourthly, evaluation of arterial blood gases (ABG) was not made and the only assessment of pulmonary gas exchange during exercise was by estimated $V \mathrm{D} / V \mathrm{~T}$ measurements. The noninvasive determination of $V \mathrm{D} / V \mathrm{~T}$, as opposed to $\mathrm{ABG}$-determined $V \mathrm{D} / V \mathrm{~T}$ measurements, may not be reliable and is known to produce higher $V \mathrm{D} / V \mathrm{~T}$ values in patients without significant lung disease [27]. This may account for the high values noted at rest in some patients (table 5). Nonetheless, the normal decreasing $V \mathrm{D} / V \mathrm{~T}$ response to incremental exercise in all of the patients with high resting values $(>0.4)$ is further indication of the absence of significant lung abnormalities in these patients.

In conclusion, residual pulmonary function defects were detected in half of the recovered severe acute respiratory syndrome patients 3 months after hospital discharge, but the impairment was mild in almost all cases. Maximum exercise capacity was below the lower limit of the normal range in $41 \%$ of the patients. In most of the patients with reduced exercise capacity, the exercise limitation cannot be accounted for by impairment in pulmonary function, suggesting extrapulmonary causes for the functional outcomes of these patients.

Acknowledgements. The authors would like to thank research coordinators, $M$. Lee and
M. Leaw, for their dedicated assistance, as well as the staff of the Respiratory Function Laboratory, Tan Tock Seng Hospital, Singapore, for their contribution to this study.

\section{References}

1. Ksiazek TG, Erdman D, Goldsmith CS, et al. A novel coronavirus associated with severe acute respiratory syndrome. N Engl J Med 2003; 348: 1953-1966.

2. Herridge MS, Cheung AM, Tansey CM, et al. One-year outcomes in survivors of the acute respiratory distress syndrome. N Engl J Med 2003; 348: 683-693.

3. World Health Organization. Update 49-SARS case fatality ratio, incubation period, 2003. www.who.int/csr/sarsarchive/ 2003_0 5_07a/en/. Date last updated: 7 May 2003. Date last accessed: 15 December 2003.

4. Hsu LY, Lee CC, Green JA, et al. Severe acute respiratory syndrome (SARS) in Singapore: clinical features of index patient and initial contacts, 2003. www.cdc.gov/ncidod/EID/ vol9no6/03-0264.htm. Date last accessed: 20 December 2003.

5. World Health Organization. Case definitions for surveillance of severe acute respiratory syndrome (SARS), 2003 www.who.int/csr/sars/casedefinition/en/. Date last accessed: 21 December 2003.

6. American Thoracic Society. Standardization of spirometry. Am J Respir Crit Care Med 1995; 152: 1107-1136.

7. American Thoracic Society. Evaluation of impairment/ disability secondary to respiratory disorders. Am Rev Respir Dis 1986; 133: 1205-1209.

8. Quanjer PH, Tammeling GJ, Cotes JE, Pedersen OF, Peslin $\mathrm{R}$, Yernault JC. Lung volumes and forced ventilatory flows. Standardized Lung Function Testing. European Community for Steel and Coal. Official Statement of the European Respiratory Society. Eur Respir J Suppl 1993; 16: 5-40.

9. American Thoracic Society. Single-breath carbon monoxide diffusing capacity (transfer factor): recommendations for a standard technique: 1995 update. Am J Respir Crit Care Med 1995; 152: 2185-2198.

10. Chia SE, Wang YT, Chan OY, Poh SC. Pulmonary function in healthy Chinese, Malay and Indian adults in Singapore. Ann Acad Med Singapore 1993; 22: 878-884.

11. Poh SC, Chia M. Respiratory function tests in normal adult Chinese in Singapore. Singapore Med J 1969; 10: 265-271.

12. ERS Task Force on Standardization of Clinical Exercise Testing. Clinical exercise testing with reference to lung diseases: indications, standardization and interpretation strategies. Eur Respir J 1997; 10: 2662-2689.

13. Beaver WL, Wasserman K, Whipp BJ. A new method for detecting anaerobic threshold by gas exchange. $J$ Appl Physiol 1986; 60: 2020-2027.

14. Borg GA. Psychophysical bases of perceived exertion. Med Sci Sports Exerc 1982; 14: 377-381.

15. Ong KC, Loo CM, Ong YY, Chan SP, Earnest A, Saw SM. Predictive values for cardiopulmonary exercise testing in sedentary Chinese adults. Respirology 2002; 7: 225-231.

16. Wong KT, Antonio GE, Hui DS, et al. Severe acute respiratory syndrome: radiographic appearances and pattern of progression in 138 patients. Radiology 2003; 228: 401-406.

17. Kor AC, Ong KC, Earnest A, Wang YT. Prediction of the maximal voluntary ventilation in healthy adult Chinese subjects. Respirology 2004 (in press).

18. Peng M, Cai BQ, Liu T, et al. Assessment of pulmonary function in SARS patients during the convalescent period. Zhongguo Yi Xие Ke Xие Yиan Xие Baо 2003; 25: 529532.

19. Han Y, Geng H, Feng W, et al. A follow-up study of 69 discharged SARS patients. J Tradit Chin Med 2003; 23: 214 217. 
20. Jin $\mathrm{ZY}$, You $\mathrm{H}$, Zhang $\mathrm{WH}$, et al. Thoracic high resolution CT findings of 100 SARS patients in convalescent period. Zhongguo Yi Xue Ke Xue Yuan Xue Bao 2003; 25: 512-515.

21. Luhr O, Aardal S, Nathorst-Westfelt U, et al. Pulmonary function in adult survivors of severe acute lung injury treated with inhaled nitric oxide. Acta Anaesthesiol Scand 1998; 42: 391-398.

22. Herridge MS. Long-term outcomes after critical illness. Curr Opin Crit Care 2002; 8: 331-336.

23. Sue DY. Evaluation of impairment and disability: the role of cardiopulmonary exercise testing. In: Weisman IM, Zeballos RJ, eds. Clinical exercise testing. Basel, Karger, 2002; pp. 217-230.
24. Neder JA, Nery LE, Bagatin E, Lucas SR, Ancao MS, Sue DY. Differences between remaining ability and loss of capacity in maximum aerobic impairment. Braz J Med Biol Res 1998; 31: 639-646.

25. Oren A, Sue DY, Hansen JE, Torrance DJ, Wasserman K. The role of exercise testing in impairment evaluation. Am Rev Respir Dis 1987; 135: 230-235.

26. Neff TA, Stocker R, Frey HR, Stein S, Russi EW. Longterm assessment of lung function in survivors of severe ARDS. Chest 2003; 123: 845-853.

27. Zeballos RJ, Weisman IM. Behind the scenes of cardiopulmonary exercise testing. Clin Chest Med 1994; 15: 193213. 